\title{
Strategic Trade and Transport Policies with Congestible Facilities
}

\author{
Andrew Yuen a and Anming Zhang, \\ ${ }^{a}$ University of British Columbia
}

\begin{abstract}
This paper investigates strategic trade and transport policies in situations where transportation of traded goods involves congestible facilities (here, roads) of both the importing and exporting countries. It is found that the presence of road congestion can have an important effect on strategic trade policies of both countries. In particular, with perfectly competitive exporting firms and hence an absence of the rent-extraction incentive, the importing country may still impose a positive tariff. Furthermore, when regional free trade blocs remove trade barriers, whether the countries can impose discriminatory road tolls between the local users and the traded-good traffic can affect: With uniform tolls, road tolls, while being regarded as a domestic (internal) policy, may serve partially as strategic trade policies. In this case, local highway users tend to be worse off than in the absence of trade liberalization. This analysis also provides a potential explanation for the "border effect."
\end{abstract}

JEL Classification: F13, L13, L91

Keywords: Strategic trade policy, transportation facilities, congestion pricing, market power, trade liberalization, border effect

\section{Introduction}

The "border effect" has been extensively explored in the trade literature since McCallum (1995). The effect refers to the observation made by a large number of recent empirical studies that national borders reduce international trade flows and increase homecountry trade flows substantially (e.g., McCallum, 1995; Wei, 1996; Engel and Rogers, 1996; Parsley and Wei, 2001; Evans, 2003). For instance, trade in goods is 10 times more likely within Canada than across the border with the United States, other things equal,

\footnotetext{
* Contact author: Anming Zhang, Sauder School of Business, University of British Columbia, 2053 Main Mall, Vancouver, BC, Canada V6T 1Z2. E-mail: anming.zhang@sauder.ubc.ca. The authors are very grateful to an anonymous referee for extensive and constructive comments. They also thank Jim Brander (the Consulting Editor), Kenneth Chan, Robert Driskill, Hong Hwang, Kazuharu Kiyono, Kevin Milligan and participants of the APJAE Symposium on Strategic Trade Theory and Economic Development held at the City University of Hong Kong in May 2007 for helpful comments on an earlier version of the paper.
} 
although the two countries are so similar in terms of culture, language and institutions, and have signed a free trade agreement. The significance of transportation's contribution to this effect has been studied in these papers: The correlation between the (log) distance between regions, as a proxy for transportation costs, and the trade volumes is found to be statistically significant. However, the potential importance of cross-border coordination in transportation facilities involved in the transportation of traded goods and the facilities' congestion in explaining the effect is less discussed in the literature, although Limao and Venables (2001) and Anderson and Van Wincoop (2004) have emphasized the dependence of time costs incurred in trade on transportation infrastructure. ${ }^{1}$ In practice, the time costs incurred in trade are affected in an important way by congestion at those transportation facilities, ${ }^{2}$ which are usually operated by different countries. For example, the transportation of auto parts from Ontario to Detroit may involve the highway systems of both Canada and the U.S., which are increasingly congested.

This paper investigates strategic trade and transport policies in situations where the transportation of traded goods involves congestible transport facilities of both the importing and exporting countries. In particular, the paper attempts to integrate local transport issues into strategic trade policy considerations, and so it is closely related to the strategic trade policy literature in which a trade policy conditions or alters a strategic relationship between oligopoly firms (see Brander, 1995, for a comprehensive review). In this literature, transportation of traded goods and related congestion costs are usually abstracted away. ${ }^{3}$ In practice, goods need to be transported from an exporting country to an importing country, while the transportation facilities involved are increasingly congested. As a consequence, firms incur costs due not only to trade barriers but also to congestion delays, which lead to additional staff and fuel expenses. Hummels (2001) finds that controlling for the distance, each additional day spent in transport from/to a country reduces the probability that the U.S. will source from that country by 1.0 to $1.5 \%$, while time cost in travel is on average equivalent to a $16 \%$ ad valorem tariff. ${ }^{4}$ In addition, firms are required to increase their inventories so as to prevent the shortage of inputs in production and goods to sell if delivery times are uncertain due to congestion delays. ${ }^{5}$ As trading firms use common transportation facilities for delivering their goods, each

${ }^{1}$ Other sources for the border effect, including exchange rate variability, transaction costs, information and communication costs, different standards and customs, are also explored in the literature.

2 Here are two examples. 1) The port facility: in the first six months of 2005, there was a ship queue of around 50 vessels anchored at any one time for an average of 21 days at Queensland's Dalrymple Bay Coal Terminal, which cost the coal industry around \$2 million per day (Everett, 2006). 2) The inland transport facility: Carruthers and Bajpai (2002) reported that within China, transporting a container from a central city to a port cost three times, owing largely to inland facility congestion, as much as shipping it from the port to America.

${ }^{3}$ Following the seminal work by Samuelson (1954), transportation costs have been considered in other branches of the international trade literature, especially the studies in new economic geography (e.g., Krugman, 1991a, 1991b; Krugman and Venables, 1995; Kose and Yi, 2001), in the form of "iceberg" costs. While the iceberg transportation costs offer analytical convenience, they are hardly empirically observable (McCann, 2005). More recently, Laussel and Riezman (2006) consider a fixed transportation cost and argued that the existence of such costs can help explain the low volume of North-South trade.

${ }^{4}$ The average ocean travel time is suggested to be 20 days.

5 Gausch and Kogan (2001) find that halving inventories could reduce unit production costs by 20 percent. 
firm's output decision may affect other firms' costs (and profits) through the congestion at the facilities. Thus, taking the congestion costs into account in trade and transport policies may alter the strategic relationship between oligopoly firms. In particular, a trade policy may change the congestion level at transport facilities, which in turn may affect firms' output decisions and profits. This paper will now discuss how the presence of local facility congestion affects countries' strategic trade policies.

To be more specific, a single transportation facility in each country, highway, will be considered. ${ }^{6}$ This paper is thus related to the road transportation literature, in which road congestion issues have been extensively discussed (for literature surveys see Small, 1992, and Small and Verhoef, 2007). The theory demonstrates that road usage may be excessive because each atomistic user does not take into account the congestion he or she imposes on others. Thus, a congestion toll is needed so as to internalize the externalities and achieve social optimum. However, in this literature facility (road) users are usually confined to a single country. ${ }^{7}$ Further, the market structure of trading firms using the road service is restricted to perfect competition; as a result, strategic trade policy issues do not arise. As trade liberalization over the last four decades has significantly stimulated trade across countries, an increasing proportion of road traffic is related to the movement of traded goods. Therefore, domestic transport policies such as highway tolls and investment may now have implications for the trade flow, which in turn can affect the highway usage and congestion delays. In other words, the domestic transport policies may have an important bearing on strategic trade policy, an issue that has yet been addressed in the road transportation literature.

This paper attempts to examine the interaction between trade and transport policies with congestible local transport facilities. Specifically, a stylized two-country threemarket model is considered, in which oligopoly firms in an exporting country produce a good and then export the output to another (importing) country. Transportation of the traded good involves the highways of both countries which are congestible. Meanwhile, there are also local users using the highways of their respective countries. Each country chooses its trade and transport policies to maximize national welfare, taking the subsequent firms' and consumers' reactions into account.

This analysis shows that the presence of road congestion can have an important effect on strategic trade policies of both countries. Specifically, the exporting country sets its export tax at the level so as to induce full internalization of the congestion costs, as well as a cartel outcome, in the export market; while the importing country sets its tariff both to balance its consumer surplus and rent-extraction considerations, and to deal with congestion. In particular, with perfect competition in the exporting industry and hence an absence of the rent-extraction incentive, the importing country still imposes a positive tariff.

This analysis further finds that when regional free trade blocs remove trade barriers ("trade liberalization"), whether the countries can impose discriminatory highway tolls between the local highway users and the traded-good traffic can have an important effect

\footnotetext{
${ }^{6}$ Although highways are considered in this paper, our analysis may also apply to other transportation facilities including both the nodes (e.g., seaport, airport) and links (e.g., rail lines, waterways).

${ }^{7}$ A few exceptions include a recent paper by De Borger, Dunkerly and Proost (2007).
} 
on trade. With discriminatory tolls, trade liberalization would yield the same equilibrium outcome as if trade were still subject to trade barriers. With uniform tolls, highway tolls, while being regarded as a domestic (internal) policy, may serve partially as strategic trade policies. In this case, local highway users tend to be worse off than in the absence of trade liberalization. Finally, this analysis provides a potential explanation for the border effect noted above. As to be shown below, the explanation is based largely on the dual role of highway tolls under trade liberalization - as both a congestion-controlling domestic transport policy and a strategic trade policy - even if the countries are confined to a uniform tolling scheme. This result may have useful implications for policy-making as well as for further empirical testing of the border effect.

The paper is organized as follows: Section 2 sets up the model, and Section 3 analyzes firm behavior in the traded-good market. Section 4 investigates the trade and transport policies, and Section 5 looks at the effects of trade liberalization under both the discriminatory and uniform tolls. Section 6 contains the concluding remarks.

\section{Basic Model}

This analysis considers a model with two countries - one exporting country, $A$, and one importing country, $B$ - and three markets: likely the simplest structure in which trade and transport issues can be addressed. As depicted in Figure 1, $N$ firms in country $A$ produce a homogenous good and then export the output to country $B$. Note that there is no domestic demand for the good in $A$, no production of the good in $B$, and no potential entry into this product market by firms in either country.

Figure 1

\section{Model Structure}

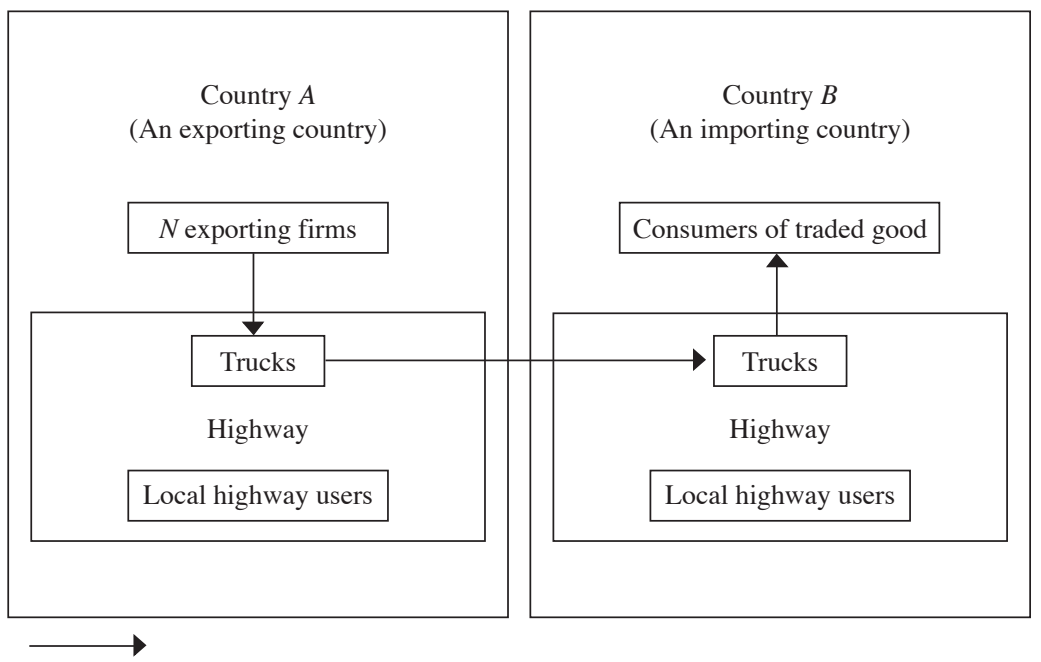

The flow of traded good 
Furthermore, the traded good is delivered to country $B$ 's consumers via trucking which involves highways of both countries. These highways are also used by "local users" of their respective countries: whilst the trucks use highways of both countries, local users are country-specific. Road users, including both the trucks and local users, are assumed atomistic so that each user is small relative to total traffic. This assumption is common in the road pricing literature (Small, 1992; Small and Verhoef, 2007).

The problem is modeled as a two-stage game: in the first stage, each country chooses its trade and transport policies to maximize national welfare. For the exporting country, this involves the choice of an export tax and a highway toll; for the importing country, a tariff and a highway toll. In the second stage, the firms compete in Cournot fashion in the traded good market. Then, demands for the traded good and the local highway traffic are realized and payoffs are made.

The subgame perfect Nash equilibrium of this game is examined, starting in this section with an analysis of demands. As indicated earlier, the highways are congestible; as a result, road users may face highway tolls (per vehicle trip) charged by their respective countries, denoted by $\tau_{A}$ and $\tau_{B}$ respectively. Note that a uniform toll is imposed on both the trucks and local highway users. ${ }^{8}$ The congestion level at a specific facility (highway) depends on total traffic at the facility, $V_{m}$, and its capacity, $K_{m}$, for $m=A, B$. Thus, in addition to highway tolls, road users may suffer from congestion delays. In particular, given the highway toll and congestion level, the "full price" faced by country $m$ 's local highway users, $\rho_{m}$, is given by:

$$
\rho_{m}=D_{m}\left(V_{m} / K_{m}\right)+\tau_{m}
$$

where $D_{m}\left(V_{m} / K_{m}\right)$ represents the congestion delay cost in country $m$. This delay cost depends on the highway volume-capacity ratio $V_{m} / K_{m}$, with the conventional assumption of $D_{m}^{\prime}(\cdot)>0$ and $D_{m}^{\prime \prime}(\cdot) \geq 0$. This paper assumes that the highway capacity $K_{m}$ is exogenously given and its investment is sunk.

To specify $V_{m}$, we use $X_{k}$ to denote the output produced by firm $k$; hence, $X=\sum_{k} X_{k}$ is total output of the traded good. Total traffic may then be expressed as:

$$
V_{m}=Y_{m}+\alpha(X)
$$

where $Y_{m}$ and $\alpha(X)$ denote, respectively, the number of trips by local highway users in country $m$ (hereafter, "local highway traffic") and the number of trips by trucks for the traded good (hereafter, "traded-good traffic"). Here, although the contributions to

${ }^{8}$ As can be easily seen below, whether the countries can set discriminatory highway tolls between the local users and the traded-good traffic won't affect our results in both the national welfare-maximizing case and the global welfare-maximizing case analyzed in Section 4 (because in those two cases, only the sum of congestion tolls and trade taxes matters), but it will affect the results under trade liberalization. The latter is discussed in Section 5 where both the uniform and discriminatory highway tolls are examined. 
congestion by the two traffic types may not be the same, the equivalence factor is simply left as one. ${ }^{9} \alpha(X)=X$ is further normalized in the analysis.

The demand of local highway users depends on the full price:

$$
P_{m}\left(Y_{m}\right)=\rho_{\mathrm{m}}
$$

where $P_{m}\left(Y_{m}\right)$ denotes the inverse demand function, with $P_{m}^{\prime}<0$ (i.e., a downwardslopping demand). By equations (1) and (2), the local highway traffic in country $m$ can be written as:

$$
Y_{m}=z_{m}\left(\tau_{m}, X\right)
$$

where, as indicated above, $\tau_{m}$ is determined in stage 1 of the game and $X$ in stage 2 . The following results characterize function (3):

Lemma 1. For $m=A, B$, (i) $\partial Y_{m} / \partial \tau_{m}<0$, i.e., an increase in highway toll will reduce the local highway traffic, indicating a downward-sloping demand function; (ii) $\partial Y_{m} / \partial X<0$, i.e., an increase in the traded-good traffic will reduce the local highway traffic; and (iii) $\partial V_{m} / \partial X>0$, i.e., an increase in the traded-good traffic will, while reducing the local highway traffic, increase the total traffic in each country.

Proof: Application of the implicit function theorem to (1) and (2) leads to:

$$
\begin{gathered}
\frac{\partial Y_{m}}{\partial \tau_{m}}=\frac{\partial z_{m}}{\partial \tau_{m}}=\frac{1}{P_{m}^{\prime}-D_{m}^{\prime} / K_{m}}<0 \\
\frac{\partial Y_{m}}{\partial X}=\frac{\partial z_{m}}{\partial X}=\frac{D_{m}^{\prime} / K_{m}}{P_{m}^{\prime}-D_{m}^{\prime} / K_{m}}<0 \\
\frac{\partial V_{m}}{\partial X}=1+\frac{\partial z_{m}}{\partial X}=\frac{P_{m}^{\prime}}{P_{m}^{\prime}-D_{m}^{\prime} / K_{m}}>0
\end{gathered}
$$

where conditions $P_{m}^{\prime}<0$ and $D_{m}^{\prime}(\cdot)>0$ are used in signing the terms. Q.E.D.

The rationale behind part (ii) of Lemma 1 is: An increase in the traded-good traffic will, with other things equal, increase highway congestion and hence the full cost for the local users, which in turn reduces their demand. Furthermore, Lemma 1 (iii) indicates that a unit increase in the traded-good traffic will outweigh the offsetting loss in the local highway traffic, leading to an overall increase in total traffic. These properties are very useful in our subsequent analysis.

${ }^{9}$ For instance, for local private cars, a "private car equivalence" ratio of 3 or 4 for each freight truck movement is used in Berechman (2007) who studies the social costs of additional traffic in the congested New Jersey highway system due to the expansion of the Port of New York. 


\section{Output Market Competition}

This section examines the second-stage Cournot competition among the $N$ exporting firms. These firms are assumed symmetric in that they have a zero fixed cost and a constant unit cost $C_{k}=C$ (for $k=1,2, \ldots, N$ ), which includes both the production and transportation costs (excluding highway tolls). The firms also need to pay highway tolls of the two countries: given the $\alpha(X)=X$ normalization, the per-unit highway toll on the traded good in country $m$ is equal to $\tau_{m}$. In addition, the firms face a per-unit tax imposed by country $A$, denoted $t_{A}$, and a per-unit tariff by country $B$, denoted $t_{B}$. Finally, highway delays cost both the exporting firms and local users. It is assumed that, without loss of generality, the cost of an hour of delay to a truck is equal to that to a local user. ${ }^{10}$ Thus, the firms face the following total cost of supplying a unit of the traded good:

$$
C+\sum_{m=A, B}\left[D_{m}\left(V_{m} / K_{m}\right)+t_{m}+\tau_{m}\right]
$$

Note that the "full" transportation cost considered in (4) can arise in one of the following two ways. First, each exporting firm has its own (in-house) logistic department and operates a trucking fleet itself. Alternatively, the firms outsource the transport operation to independent trucking firms that are perfectly competitive. As a consequence, the price charged by the atomistic trucking firms to the exporting firms is just equal to the full marginal cost. ${ }^{11}$ In both cases, it is assumed that delivery of the traded good must use the said trucking transport service. This assumption is sensible especially in the short run as the substitution among transport modes is unlikely to be feasible given the existing transportation network, geographical limitation and product characteristics. The substitution between transport service and other inputs would be even more difficult. ${ }^{12}$

Each firm, $k$, chooses quantity to maximize its profit:

$$
\underset{X_{k}}{\operatorname{Max}} \pi_{k}\left(X_{k}\right)=P_{X} X_{k}-\left\{C+\sum_{m=A, B}\left[D_{m}\left(V_{m} / K_{m}\right)+t_{m}+\tau_{m}\right]\right\} X_{k}
$$

where $P_{X}$ is the price of the traded good. Hence, the inverse demand is given by $P_{X}=P_{X}(X)$ with $P_{X}^{\prime}<0$. The Cournot equilibrium is characterized by the first-order conditions,

\footnotetext{
${ }^{10}$ In practice, the cost of an hour of delay for a truck is usually greater than that for a car. For instance, US DOT (2003) recommends a value of travel time between \$10.6/hour and \$21.2/hour (in 2000 US\$) for cars and light trucks, depending on the purpose of the trip (personal, commuting, or "on-the-clock" travel). On the other hand, Levinson and Smalkoski (2003) find a mean value of $\$ 49.42 /$ hour for commercial vehicle operators in Minnesota, whereas De Jong (2000) finds a range of values from \$36/hour to \$48/hour. Further discussion about implications of the difference in time valuations can be found in Yuen, Basso and Zhang (2007).

${ }^{11}$ If the transport services sector were imperfectly competitive, then the transport price would be greater than the marginal cost and the associated strategic behaviors need to be analyzed. The issue will be discussed further in the concluding remarks.

${ }^{12}$ In the longer term, substitution between the transport service and other inputs may be feasible. The issue will be discussed further in the concluding remarks.
} 


$$
\frac{\partial \pi_{k}}{\partial X_{k}}=P_{X}-\left[C+\sum_{m=A, B}\left(D_{m}+t_{m}+\tau_{m}\right)\right]+X_{k}\left[P_{X}^{\prime}-\sum_{m=A, B} \frac{\partial V_{m}}{\partial X} \frac{D_{m}^{\prime}}{K_{m}}\right]=0, \forall k
$$

and second-order conditions $\partial^{2} \pi_{k} / \partial X_{k}^{2}<0, \forall k$. It is further assumed that a firm's marginal profit declines when another firm's output rises:

$$
\frac{\partial^{2} \pi_{k}}{\partial X_{k} \partial X_{j}}<0, \quad j \neq k
$$

Conditions (7) imply the firms' outputs are "strategic substitutes" (Bulow, Geanakoplos and Klemperer, 1985) and ensure that various comparative static properties are "well defined" (see Dixit, 1986).

By (6), imposing symmetry and adding up, the following is obtained:

$$
P_{X}=C+\sum_{m=A, B}\left(D_{m}+t_{m}+\tau_{m}\right)+\frac{1}{N} \sum_{m=A, B} \frac{\partial V_{m}}{\partial X} \frac{X D_{m}^{\prime}}{K_{m}}+\frac{1}{N} \frac{P_{X}}{\varepsilon_{X}}
$$

where $\varepsilon_{\mathrm{x}} \equiv-\left(\partial X / \partial P_{x}\right)\left(P_{x} / X\right)=-P_{x} / P_{x}^{\prime} X$ denotes the (positive) demand elasticity of the traded good with respect to price. In the absence of highway congestion - i.e., $D_{m}=D_{m}^{\prime}=0$ - the price in (8) exceeds the marginal cost by a positive value of $(1 / N)\left(P_{x} / \varepsilon_{x}\right)$. In other words, a monopoly/oligopoly "rent" is paid by the importing country to the foreign firms. The extent of the rent depends on the degree of market power, which is captured here by the number of firms $N$. The larger is the $N$ (the less the market power), the smaller is the rent.

When the transportation facilities are congestible, the first two terms in (8) are the "average cost" incurred by each firm, which includes the delay costs in the two countries. The third term in (8) is related to congestion costs imposed by the firms supplying the traded good. This term is positive - recall, by Lemma $1, \partial V_{m} / \partial X>0-$ and reflects the fact that each firm will internalize the congestion imposed on its own traffic, but not that imposed on other firms' traffic. In other words, each firm will only consider the impact of its output decision on the average cost which affects the firm itself (i.e., $\left.(\mathrm{X} / N) \sum_{m=A, B}\left(\partial D_{m} / \partial X\right)\right)$ but not its rivals. For a monopoly firm, $N=1$, the marginal congestion cost is fully internalized (charged). Thus the first three terms are equal to the full marginal cost. On the other extreme, for atomistic (perfectly competitive) firms, $N \rightarrow \infty$, the congestion cost is totally uninternalized and the price is equal to the average cost incurred by the firms. For $1<N<\infty$, partial internalization is obtained, and the first three terms in (8) are greater than the average cost but less than the full marginal cost. This result is similar to the one in the airport congestion pricing literature (e.g., Brueckner, 2002): each oligopoly airline at an airport only internalizes the congestion one of its flights imposing on its other flights but not that on other airlines' flights.

Next, the comparative-static effects are derived with respect to policy variables $t_{m}$ and $\tau_{m}$ (for $m=A, B$ ) chosen in the first stage. The results are as follows.

Lemma 2. For $m=A, B$, (i) $\partial X / \partial t_{m}<0$, i.e., the aggregate traded-good output decreases in both export tax and import tariff; and (ii) the sign of $\partial X / \partial \tau_{m}$ is in general undetermined. In the special case of zero highway congestion, we have $\partial X / \partial \tau_{m}=\partial X / \partial t_{m}$, 
indicating that the aggregate traded-good output decreases in highway tolls of each country.

Proof: Totally differentiating conditions (6) with respect to $t_{m}$ and $\tau_{m}$, and solving the resulting equations, we obtain:

$$
\begin{aligned}
& \frac{\partial X}{\partial t_{m}}=\frac{N}{\Omega} \\
& \frac{\partial X}{\partial \tau_{m}}=\frac{\partial X}{\partial t_{m}}+\left(N \frac{D_{m}^{\prime}}{K_{m}}+\frac{\partial V_{m}}{\partial X} \frac{X D_{m}^{\prime \prime}}{K_{m}^{2}}\right) \frac{\partial Y_{m}}{\partial \tau_{m}} / \Omega
\end{aligned}
$$

with

$$
\Omega \equiv(N+1)\left(P_{X}^{\prime}-\sum_{m=A, B} \frac{\partial V_{m}}{\partial X} \frac{D_{m}^{\prime}}{K_{m}}\right)+P_{X}^{\prime \prime} X-X \sum_{m=A, B}\left[\left(\frac{\partial V_{m}}{\partial X} \frac{1}{K_{m}}\right)^{2} D_{m}^{\prime \prime}+\frac{\partial^{2} Y_{m}}{\partial X^{2}} \frac{D_{m}^{\prime}}{K_{m}}\right] .
$$

By the second-order conditions and conditions (7), it follows that $\Omega<0$ and so $\partial X / \partial t_{m}<0$. On the other hand, there are two terms in (10). The first term is $\partial X / \partial t_{m}$, which is negative as indicated above: conditional on the congestion level, an increase in highway tolls (like an export tax or an import tariff) increases firms' cost, thereby reducing their output. But the second term is, by Lemma 1, positive, showing that an increase in highway tolls reduces the local highway traffic and hence highway congestion, which in turn reduces firms' "full cost," thereby increasing their output. These two opposite impacts lead to the sign of $\partial X / \partial \tau_{m}$ being in general undetermined. In the special case of zero highway congestion, we have $\partial X / \partial \tau_{m}=\partial X / \partial t_{m}$, suggesting a negative relationship between $X$ and $\tau_{m}$.

Q.E.D.

\section{Trade and Transport Policies}

The above analysis shows that trade and transport policies will affect both firm and consumer behavior. Taking this into account, each country chooses, in the first stage, its trade and transport policies to maximize national welfare. For country $A$, its government chooses export tax and highway toll to maximize its social welfare $S W_{A}$ :

$$
\underset{t_{A}, \tau_{A}}{\operatorname{Max}} S W_{A}=C S_{A}+\sum_{k} \pi_{k}+\left[\left(Y_{A}+X\right) \tau_{A}+X t_{A}\right]
$$

where $S W_{A}$ is the sum of consumer surplus $\left(C S_{A}\right)$, the aggregate profit of its firms, and the government revenues, which are the sum of highway toll revenue and tax revenue from the traded good. ${ }^{13} C S_{A}$ is assumed to arise from a utility function that can be approximated by the form:

${ }^{13}$ Without loss of generality the highway operational costs are set to zero. Recall further that, since the highway investment is sunk, the capacity costs are not considered. 


$$
u_{A}\left(Y_{A}\right)+\phi_{A}
$$

where $\phi_{A}$ is the expenditure on other goods in country $A$ and its composite price is normalized to unity, with $\partial u_{A} / \partial Y_{A}=D_{A}\left(V_{A} / K_{A}\right)+\tau_{A}$. Thus,

$$
C S_{A}=u_{A}\left(Y_{A}\right)-\left[D_{A}\left(V_{A} / K_{A}\right)+\tau_{A}\right] Y_{A}
$$

where parameter $\phi_{A}$ is suppressed for notational simplicity.

Similarly, country $B$ 's problem can be expressed as:

$$
\underset{t_{B}, \tau_{B}}{\operatorname{Max}} S W_{B}=C S_{B}+\left[\left(Y_{B}+X\right) \tau_{B}+X t_{B}\right]
$$

Different from the consumer surplus of country $A$ which is concerned with only $A$ 's local highway users, however, consumer surplus in country $B\left(C S_{B}\right)$ includes two consumer groups: both its local highway users and consumers of the traded good. As a result, $C S_{B}$ is written as:

$$
C S_{B}=u_{B}\left(Y_{B}, X\right)-\left[D_{B}\left(V_{B} / K_{B}\right)+\tau_{B}\right] Y_{B}-P_{X} X
$$

where $Y_{B}$ and $X$ are assumed to be separable and uncorrelated in the utility function.

The first-order conditions for (11) and (12) with respect to $\tau_{A}, t_{A}, \tau_{B}$ and $t_{B}$ are given in (13)-(16), respectively:

$$
\begin{aligned}
& {\left[\tau_{A}-\frac{\left(Y_{A}+X\right) D_{A}^{\prime}}{K_{A}}\right] \frac{\partial Y_{A}}{\partial \tau_{A}}} \\
& +\left[\tau_{A}+t_{A}-\frac{Y_{A} D_{A}^{\prime}}{K_{A}}-\frac{N-1}{N}\left(\sum_{m=A, B} \frac{\partial V_{m}}{\partial X} \frac{X D_{m}^{\prime}}{K_{m}}+\frac{P_{X}}{\varepsilon_{X}}\right)+\frac{X D_{A}^{\prime}}{K_{A}} \frac{\partial Y_{A}}{\partial X}\right] \frac{\partial X}{\partial \tau_{A}}=0 \\
& {\left[\tau_{A}-\frac{\left(Y_{A}+X\right) D_{A}^{\prime}}{K_{A}}\right] \frac{\partial Y_{A}}{\partial t_{A}}} \\
& +\left[\tau_{A}+t_{A}-\frac{Y_{A} D_{A}^{\prime}}{K_{A}}-\frac{N_{-1}}{N}\left(\sum_{m=A, B} \frac{\partial V_{m}}{\partial X} \frac{X D_{m}^{\prime}}{K_{m}}+\frac{P_{X}}{\varepsilon_{X}}\right)+\frac{X D_{A}^{\prime}}{K_{A}} \frac{\partial Y_{A}}{\partial X}\right] \frac{\partial X}{\partial t_{A}}=0 \\
& \left(\tau_{B}-\frac{Y_{B} D_{B}^{\prime}}{K_{B}}\right) \frac{\partial Y_{B}}{\partial \tau_{B}}+\left(\tau_{B}+t_{B}-\frac{Y_{B} D_{B}^{\prime}}{K_{B}}+\frac{P_{X}}{\varepsilon_{X}}\right) \frac{\partial X}{\partial \tau_{B}}+X=0 \\
& \left(\tau_{B}-\frac{Y_{B} D_{B}^{\prime}}{K_{B}}\right) \frac{\partial Y_{B}}{\partial t_{B}}+\left(\tau_{B}+t_{B}-\frac{Y_{B} D_{B}^{\prime}}{K_{B}}+\frac{P_{X}}{\varepsilon_{X}}\right) \frac{\partial X}{\partial t_{B}}+X=0
\end{aligned}
$$

These conditions jointly determine the equilibrium trade and transport policies, denoted $\left(\tau_{A}^{N W}, t_{A}^{N W}, \tau_{B}^{N W}, t_{B}^{N W}\right)$ (superscript $N W$ for national welfare maximization).

After some tedious manipulations of (13) to (16), the following can be obtained: 


$$
\begin{aligned}
\tau_{A}^{N W} & =\frac{\left(Y_{A}+X\right) D_{A}^{\prime}}{K_{A}} \\
t_{A}^{N W} & =\frac{N-1}{N} \frac{P_{X}}{\varepsilon_{X}}+\frac{\partial V_{B}}{\partial X} \frac{X D_{B}^{\prime}}{K_{B}}-\frac{1}{N} \sum_{m=A, B} \frac{\partial V_{m}}{\partial X} \frac{X D_{m}^{\prime}}{K_{m}} \\
\tau_{B}^{N W} & =\frac{\left(Y_{B}+X\right) D_{B}^{\prime}}{K_{B}}+\frac{1}{N} \frac{\partial V_{B}}{\partial X} \frac{X^{2} D_{B}^{\prime \prime}}{K_{B}^{2}} \\
t_{B}^{N W} & =\frac{1}{N}\left(\frac{P_{X}}{\varepsilon_{X}}-X^{2} P_{X}^{\prime \prime}\right)+\frac{1}{N}\left[\frac{\partial V_{B}}{\partial X} \frac{X}{K_{B}}\left(D_{B}^{\prime}-\frac{X D_{B}^{\prime \prime}}{K_{B}}\right)+\frac{\partial^{2} Y_{B}}{\partial X^{2}} \frac{X D_{B}^{\prime}}{K_{B}}\right] \\
& +\frac{1}{N}\left[(N+1) \frac{\partial V_{A}}{\partial X} \frac{X D_{A}^{\prime}}{K_{A}}+\left(\frac{\partial V_{A}}{\partial X} \frac{X}{K_{A}}\right)^{2} D_{A}^{\prime \prime}+\frac{\partial^{2} Y_{A}}{\partial X^{2}} \frac{X D_{A}^{\prime}}{K_{A}}\right]
\end{aligned}
$$

The equilibrium policies $\left(\tau_{A}^{N W}, t_{A}^{N W}, \tau_{B}^{N W}, t_{B}^{N W}\right)$ are implicitly determined by equations (17) to (20). Although it is not possible to solve them explicitly with the general specifications of demand and congestion delays used here, an examination of these policy rules still provides useful insights, as will be seen below.

\section{1 "No congestion" case}

To see how these results are related to the strategic trade policy literature, we first consider that there is no congestion at the highways (i.e., $D_{m}=D_{m}^{\prime}=D_{m}^{\prime \prime}=0$ ). In this case, equations (17) to (20) reduce to:

$$
\begin{aligned}
\tau_{A}^{N W} & =0 \\
t_{A}^{N W} & =\frac{N-1}{N} \frac{P_{X}}{\varepsilon_{X}} \\
\tau_{B}^{N W} & =0 \\
t_{B}^{N W} & =\frac{1}{N}\left(\frac{P_{X}}{\varepsilon_{X}}-X^{2} P_{X}^{\prime \prime}\right)
\end{aligned}
$$

Equations (21) and (23) show that in the absence of congestion, no highway tolls are imposed in both countries. This is because the social marginal costs of using the highways are zero in this case.

Further, equation (22) suggests that a positive export tax is imposed when $N>1$, and the tax increases with $N$. What happens is that the firms would like to collude in order to increase profit, but are unable to do so by themselves - and the greater number of firms is, the more the difficulty in achieving such collusion. By imposing the export tax, 
government $A$, as the first mover of the game, will coordinate its firms so as to achieve, tacitly, the cartel outcome in the export market. ${ }^{14}$ Understandably, the coordination is not needed when $N=1$, as the firm itself is able to achieve the monopoly outcome. Formal oligopoly models demonstrating the cartelization of exports can improve the exporting country's welfare are also found in, e.g., Auquier and Caves (1978), Dixit (1984), and Brander and Spencer (1984). ${ }^{15}$

Finally, equation (24) gives the optimal tariff rule for country $B$. As noted earlier, the firms in country $A$ enjoy a pure rent; consequently, country $B$ will have an incentive to extract part of this rent with a positive tariff (Enke, 1944; Brander and Spencer, 1981). In particular, an increase in the tariff will increase the government revenue by $[(N+1) / N]\left(P_{X} / \varepsilon_{X}\right)-(1 / N) X^{2} P_{X}^{\prime \prime}$. But an increase in tariff will hurt the consumers of the traded good in country $B$, reducing its consumer surplus by $P_{X} / \varepsilon_{X}$. The sum of these two opposing impacts then yields the optimal tariff rule (24). Specifically, a positive (negative, respectively) tariff is imposed when $\left(P_{X} / \varepsilon_{X}\right)-X^{2} P_{X}^{\prime \prime}>0(<0$, respectively). In particular, the positive tariff case will arise for a linear demand $\left(P_{X}^{\prime \prime}=0\right)$. It is noted that for perfectly competitive firms $(N \rightarrow \infty)$, no rent is available for country $B$ to extract, as the price is equal to the marginal cost. Thus, as indicated in (24), the tariff should be zero, implying that free trade is the optimal policy for country $B$. At the other extreme, for a monopoly $(N=1)$, our case reduces to the case which was first examined by Brander and Spencer (1981), who find that the importing country may gain from a tariff, as extracting some of the foreign monopoly rent can outweigh the loss in consumer surplus under certain conditions.

\subsection{Congestion case}

With highway congestion, equations (17) and (19) indicate, not surprisingly, positive highway tolls. The export tax rule is now given by (18). As discussed in Section 3, for $N>1$, each firm won't internalize the congestion caused by its traffic imposed on other firms' traffic and the price charged by the firm does not fully reflect the full marginal cost. Thus, in addition to a positive charge for cartel coordination as discussed in the no-congestion case, the export tax given in (18), together with the highway toll in (17), are imposed by country $A$ in order to induce the firms to fully internalize the congestion costs associated with the traded good traffic. In other words, country $A$ sets the highway toll and the export tax at the levels such that the full prices paid by the local highway users and consumers of the traded good reflect the full marginal costs of using its highway. This

\footnotetext{
${ }^{14}$ As suggested by an anonymous referee, an alternative explanation for the positive export tax can be based on the observation that for a downward-sloping demand curve, the marginal revenue perceived by the individual firm exceeds the industry's marginal revenue in the oligopoly market. This then leads to excessive output from the viewpoint of industry profit maximization. Taking this into account, a positive tax is imposed so as to achieve the industry's (and country's) optimum.

15 Since the firms in our model serve the foreign market only, the competitive issues in their domestic market, which are also examined in Auquier and Caves (1978), do not arise here. Furthermore, since any competition from the importing country (i.e., country $B$ ) or a third country was assumed away, the incentives for countries to strategically use export subsidies, which was first considered by Brander and Spencer (1985), do not appear here.
} 
result is similar to the airport congestion pricing literature (e.g., Brueckner, 2002; Zhang and Zhang, 2006; Basso and Zhang, 2007) which shows that a welfare-maximizing airport would impose a congestion toll in order to fully internalize the air carriers' uninternalized congestion at the airport. Similar to country $A$ 's export tax, country $B$ 's tariff also serves a dual role as both a trade policy, as discussed in the no-congestion case, and a congestion toll. This can be seen from the tariff rule (20).

The dual role for each country's trade policy can be most cleanly illustrated when market structure of the exporting industry is perfectly competitive. Letting $N \rightarrow \infty$, then (18) and (20) reduce to:

$$
\begin{aligned}
t_{A}^{N W} & =\frac{P_{X}}{\varepsilon_{X}}+\frac{\partial V_{B}}{\partial X} \frac{X D_{B}^{\prime}}{K_{B}} \\
t_{B}^{N W} & =\frac{\partial V_{A}}{\partial X} \frac{X D_{A}^{\prime}}{K_{A}}
\end{aligned}
$$

respectively. For export tax $t_{A}^{N W}$, the first term on the right-hand side (RHS) of (25) captures the cartel-coordination effect, whereas the second term is congestion toll-related. For import tariff $t_{B}^{N W}$, the rent-extraction part is, as noted earlier, zero, so the RHS of (26) represents the internalization of marginal congestion costs on the traded good. By Lemma 1 , both $t_{A}^{N W}$ and $t_{B}^{N W}$ are positive.

The above discussion leads to:

Proposition 1. With highway congestion, (i) country A's export tax is set at the level so as to induce full internalization of the congestion costs, as well as a cartel outcome, in the export market; (ii) country B's import tariff is set both to balance its consumer surplus and rent-extraction considerations, and to deal with congestion; and (iii) with perfectly competitive exporting firms and hence an absence of the rent-extraction incentive, country $B$ still imposes a positive tariff.

\subsection{Global welfare maximization}

To further understand the interaction between trade and transport policies, it is useful to examine the benchmark case of global welfare maximization, in which the two countries undertake trade and transport policies to maximize their joint welfare. The problem can be formulated as follows:

$$
\underset{\substack{\tau_{A}, \tau_{B} \\ t_{A}, t_{B}}}{\operatorname{Max}} G W=\sum_{k} \pi_{k}+\sum_{m=A, B}\left[C S_{m}+\left(Y_{m}+X\right) \tau_{m}+X t_{m}\right]
$$

The first-order conditions for (27) will lead to (superscript $G W$ for global welfare maximization):

$$
\tau_{A}^{G W}=\frac{\left(Y_{A}+X\right) D_{A}^{\prime}}{K_{A}}
$$




$$
\begin{aligned}
& \tau_{B}^{G W}=\frac{\left(Y_{B}+X\right) D_{B}^{\prime}}{K_{B}} \\
& t_{A}^{G W}+t_{B}^{G W}=-\frac{1}{N} \frac{P_{X}}{\varepsilon_{X}}-\frac{1}{N} \sum_{m=A, B} \frac{\partial V_{m}}{\partial X} \frac{X D_{m}^{\prime}}{K_{m}}
\end{aligned}
$$

Under the global welfare maximization, therefore, the optimal highway tolls in the two countries are equal to their respective full marginal congestion costs imposed on both the local users and the traded good at the highways. Note that, conditional on the aggregate output (i.e., $Y_{m}+X$ for $m=A, B$ ), $\tau_{A}^{G W}$ is the same as $\tau_{A}^{N W}$ given in (17), whilst $\tau_{B}^{G W}$ is less than $\tau_{B}^{N W}$ in (19).

The total tax on the traded good is given in (30), indicating that, for a finite $N$, a subsidy is given to the traded good under the global welfare maximization. This is partly because the profit-maximizing firms will, in the second stage, set the price higher than the marginal cost so as to exploit their market power. Anticipating this behavior, a subsidy, representing by the first term on the RHS of (30), is given to induce a lower price downstream and correct the market-power distortion. Furthermore, the total charge imposed on the traded good - i.e., the sum of highway tolls and taxes on the traded good - intends to induce the firms to fully internalize the congestion costs in their operations. This can be further illustrated in the equilibrium price of the traded good, $P_{X}^{G W}$, which can be obtained by substituting (28) to (30) into (9),

$$
P_{X}^{G W}=C+\sum_{m=A, B}\left[D_{m}+\frac{\left(Y_{m}+X\right) D_{m}^{\prime}}{K_{m}}\right]
$$

Thus, the equilibrium price is equal to the social marginal cost. This, combined with charging rules (28) and (29), leads to:

Proposition 2. Under the global welfare maximization, the highway tolls and the taxes on the traded good are set at the levels such that the full prices paid by the local highway users and consumers of the traded good are equal to their respective social marginal costs.

It is useful to further compare $P_{X}^{G W}$ with the equilibrium price under the national welfare maximization, $P_{X}^{N W}$. Substituting (17) to (20) into (9) gives:

$$
\begin{aligned}
P_{X}^{N W}= & C+\sum_{m=A, B}\left[D_{m}+\frac{\left(Y_{m}+X\right) D_{m}^{\prime}}{K_{m}}+\frac{\partial V_{m}}{\partial X} \frac{X D_{m}^{\prime}}{K_{m}}\right]+\frac{P_{X}}{\varepsilon_{X}}-\frac{1}{N} X^{2} P_{X}^{\prime \prime} \\
& +\frac{1}{N}\left[\left(\frac{\partial V_{A}}{\partial X} \frac{X}{K_{A}}\right)^{2} D_{A}^{\prime \prime}+\sum_{m=A, B} \frac{\partial^{2} Y_{m}}{\partial X^{2}} \frac{X D_{m}^{\prime}}{K_{m}}\right]
\end{aligned}
$$

The equilibrium price given in (32) is equal to that in (31) plus some additional terms. To have a better understanding on those terms, two special cases will be considered. First, consider the no-congestion case. In the absence of congestion, (32) reduces to: 


$$
P_{X}^{N W}=C+\frac{N-1}{N} \frac{P_{X}}{\varepsilon_{X}}+\frac{1}{N}\left(\frac{P_{X}}{\varepsilon_{X}}-X^{2} P_{X}^{\prime \prime}\right)
$$

That is, the equilibrium price is equal to the cost of supplying the traded good, $C$, plus two additional terms (note in the absence of congestion, $P_{X}^{G W}=C$ ). The second term on the RHS of (33) is positive, which is the export tax imposed by country $A$ so as to achieve the cartel outcome, whereas the third term is the tariff imposed by country $B$ and as discussed above, its sign is in general undetermined.

The second special case occurs when $N \rightarrow \infty$, i.e., firms in the export market are perfectly competitive. In this case, (32) reduces to:

$$
P_{X}^{N W}=C+\sum_{m=A, B}\left[D_{m}+\frac{\left(Y_{m}+X\right) D_{m}^{\prime}}{K_{m}}\right]+\sum_{m=A, B} \frac{\partial V_{m}}{\partial X} \frac{X D_{m}^{\prime}}{K_{m}}+\frac{P_{X}}{\varepsilon_{X}}
$$

Here, the equilibrium price of the traded good is greater than the social marginal cost by the amount of $\sum_{m=A, B}\left(\partial V_{m} / \partial X\right)\left(X D_{m}^{\prime} / K_{m}\right)$ (in addition to the cartel markup achieved through country $A$ 's export tax). This is because, without the cooperation between the two countries, each country attempts to internalize the congestion cost at the other country's highway, although it has already been internalized by that country's transport policy. This leads to a "double-internalization" problem. In other words, the two countries may overinternalize the congestion when there is lack of cooperation in their trade and transport policies.

Proposition 3. As compared to the global welfare maximization, the national welfare maximization may result in over-internalization of highway congestion, leading to a higher price of the traded good.

\section{Trade Liberalization}

It is also useful to compare the cases of national and global welfare maximizations analyzed in Section 4, with "trade liberalization." The latter case means a "free trade" situation where $t_{A}=0$ and $t_{B}=0$, but each country continues to choose its own highway toll to maximize national welfare - i.e., transport policies such as highway tolls are still regarded as a pure domestic (internal) policy. This case may be analogous to the establishment of a free trade area, such as the Canada-U.S. Free Trade Agreement (which was later expanded to the North American Free Trade Agreement to include Mexico), the European Union (EU) Common Market, and the Australia-New Zealand Closer Economic Relations Trade Agreement, in which the countries involved eliminate (or substantially reduce) trade barriers such as tariffs, whilst the extent of cooperation in making their domestic policies is much less.

As indicated in footnote 8 , whether the countries can set discriminatory highway tolls between the local users and the traded-good traffic won't affect these results in both the national welfare maximization and global welfare maximization. However, it plays an important role in the trade-liberalization case. In practice, the principle of "national treatment" on internal taxation - countries are not allowed to impose different taxes 
on local and foreign goods - may be included in a free trade agreement. For example, De Borger, Proost and Van Dender (2005) point out that explicit highway toll discrimination between local and transit transport contradicts EU regulations. On the other hand, transportation of traded goods can involve additional transportation facilities, such as border crossings. This might provide a justification for imposing discriminatory highway tolls based on, for example, Article III (4) of the General Agreement on Tariffs and Trade (GATT), which states that "the national treatment principle shall not prevent the application of differential internal transportation charges which are based exclusively on the economic operation of the means of transport." Both the discriminatory tolls and nondiscriminatory tolls are considered below.

\subsection{Discriminatory highway toll}

When discriminatory highway tolls are feasible, each country chooses, the maximization problems (11) and (12) are rewritten as (recall $t_{A}=t_{B}=0$ under trade liberalization):

$$
\begin{aligned}
& \operatorname{Max}_{\tau_{A}^{L}, \tau_{A}^{X}} S W_{A}=C S_{A}+\sum_{k} \pi_{k}+Y_{A} \tau_{A}^{L}+X \tau_{A}^{X} \\
& \underset{\tau_{B}^{L}, \tau_{B}^{X}}{\operatorname{Max}} S W_{B}=C S_{B}+Y_{B} \tau_{B}^{L}+X \tau_{B}^{X}
\end{aligned}
$$

where $\tau_{m}^{L}$ and $\tau_{m}^{X}$ are the discriminatory highway tolls imposed, by country $m$, on the local users and the traded good traffic, respectively.

The first-order conditions for (35) and (36) lead to (superscript $T L$ for trade liberalization):

$$
\begin{aligned}
\tau_{A}^{L T L}= & \frac{\left(Y_{A}+X\right) D_{A}^{\prime}}{K_{A}} \\
\tau_{A}^{X T L}= & \frac{\left(Y_{A}+X\right) D_{A}^{\prime}}{K_{A}}+\frac{N-1}{N} \frac{P_{X}}{\varepsilon_{X}}+\frac{\partial V_{B}}{\partial X} \frac{X D_{B}^{\prime}}{K_{B}}-\frac{1}{N} \sum_{m=A, B} \frac{\partial V_{m}}{\partial X} \frac{X D_{m}^{\prime}}{K_{m}} \\
\tau_{B}^{L T L}= & \frac{\left(Y_{B}+X\right) D_{B}^{\prime}}{K_{B}}+\frac{1}{N} \frac{\partial V_{B}}{\partial X} \frac{X^{2} D_{B}^{\prime \prime}}{K_{B}^{2}} \\
\tau_{B}^{X T L}= & \frac{\left(Y_{B}+X\right) D_{B}^{\prime}}{K_{B}}+\frac{1}{N}\left(\frac{P_{X}}{\varepsilon_{X}}-X^{2} P_{X}^{\prime \prime}\right)+\frac{1}{N}\left(\frac{\partial V_{B}}{\partial X} \frac{X D_{B}^{\prime}}{K_{B}}+\frac{\partial^{2} Y_{B}}{\partial X^{2}} \frac{X D_{B}^{\prime}}{K_{B}}\right) \\
& +\frac{1}{N}\left[(N+1) \frac{\partial V_{A}}{\partial X} \frac{X D_{A}^{\prime}}{K_{A}}+\left(\frac{\partial V_{A}}{\partial X} \frac{X}{K_{A}}\right)^{2} D_{A}^{\prime \prime}+\frac{\partial^{2} Y_{A}}{\partial X^{2}} \frac{X D_{A}^{\prime}}{K_{A}}\right]
\end{aligned}
$$

Using the expressions for national welfare-maximizing policies $\left(\tau_{A}^{N W}, t_{A}^{N W}, \tau_{B}^{N W}, t_{B}^{N W}\right)$ given in (17)-(20), (37)-(40) can simply be rewritten as: 


$$
\begin{aligned}
\tau_{m}^{L T L} & =\tau_{m}^{N W} \\
\tau_{m}^{X T L} & =\tau_{m}^{N W}+t_{m}^{N W}
\end{aligned}
$$

for $m=A, B$. Thus, the total charges imposed by countries $A$ and $B$ on the traded good and their respective local highway users in the trade-liberalization case are the same as those in the national welfare-maximizing case. In particular, equation (42) suggests that under trade liberalization, the highway toll on the trade good is increased (from the local charge) by $t_{m}^{N W}$, so that the total charge imposed by country $m$ is the same as that under the national welfare maximization. Equations (41) and (42) further suggest that the outputs $Y_{m}$ and $X$ would be the same in the two cases. In effect, while the tariff and tax rates are restricted to zero, the availability of two separate tolls allows each country to replicate the two policy instruments (i.e., the external trade policy and internal transport policy) in the case of national welfare maximization. ${ }^{16}$ This leads to the following proposition:

Proposition 4. If the discriminatory highway tolls can be imposed, the equilibrium under trade liberalization is the same as that under national welfare maximization.

This result illustrates the importance of the national-treatment provision in a free trade agreement, in terms of avoiding the countries from using internal taxes as a non-tariff barrier to trade. Without such a provision, any reduction in tariffs and trade taxes might be totally offset by an increase in domestic (internal) tax on traded goods. As a result, the trade agreement will not have any impact on the market outputs, the trade volume and the national welfare.

\subsection{Uniform highway tolls}

Next, the case of uniform tolls where countries cannot charge tolls between the local highway users and the traded-good traffic is reconsidered. By setting $t_{A}=t_{B}=0$ and rearranging conditions (13) and (15), the following optimal highway tolls are obtained:

$$
\begin{aligned}
\tau_{A}^{T L}= & \frac{Y_{A} D_{A}^{\prime}}{K_{A}}+\frac{X D_{A}^{\prime}}{K_{A}} \frac{\partial Y_{A}}{\partial \tau_{A}} /\left(\frac{\partial Y_{A}}{\partial \tau_{A}}+\frac{\partial X}{\partial \tau_{A}}\right) \\
& +\left[\frac{N-1}{N}\left(\sum_{m=A, B} \frac{\partial V_{m}}{\partial X} \frac{X D_{m}^{\prime}}{K_{m}}+\frac{P_{X}}{\varepsilon_{X}}\right)-\frac{X D_{A}^{\prime}}{K_{A}} \frac{\partial Y_{A}}{\partial X}\right] \frac{\partial X}{\partial \tau_{A}} /\left(\frac{\partial Y_{A}}{\partial \tau_{A}}+\frac{\partial X}{\partial \tau_{A}}\right) \\
\tau_{B}^{T L}= & \frac{Y_{B} D_{B}^{\prime}}{K_{B}}-\frac{P_{X}}{\varepsilon_{X}} \frac{\partial X}{\partial \tau_{B}} /\left(\frac{\partial Y_{B}}{\partial \tau_{B}}+\frac{\partial X}{\partial \tau_{B}}\right)-X /\left(\frac{\partial Y_{B}}{\partial \tau_{B}}+\frac{\partial X}{\partial \tau_{B}}\right)
\end{aligned}
$$

${ }^{16}$ Note that if the transport service can be substituted by other inputs in the traded-good production, additional policy instruments might be required to achieve the "equivalence" result. 
where $\tau_{m}^{T L}$ is the uniform toll imposed on both the local users and the traded good traffic by country $m$ under trade liberalization.

Using the expressions for national welfare-maximizing policies $\left(\tau_{A}^{N W}, t_{A}^{N W}, \tau_{B}^{N W}, t_{B}^{N W}\right)$ given in (17)-(20) we can simplify (43)-(44) as (for $m=A, B$ ):

$$
\tau_{m}^{T L}=\tau_{m}^{N W}+t_{m}^{N W} \frac{\partial X}{\partial \tau_{m}} /\left(\frac{\partial Y_{m}}{\partial \tau_{m}}+\frac{\partial X}{\partial \tau_{m}}\right)
$$

As can be seen from (45), $\tau_{m}^{T L}$, while being regarded as a domestic (internal) policy, is now "distorted" to also serve, partially, as a trade tax $\left(t_{m}^{N W}\right)$, with the relative importance being dependent on the magnitudes of $\partial Y_{m} / \partial \tau_{m}$ and $\partial X / \partial \tau_{m}$. It is noted that in the national welfare-maximizing case, the policy considerations for the local user and traded-good markets can be handled separately by the highway toll and taxes on the traded good. Under trade liberalization with uniform toll, however, each country can only impose a single toll at its facility (highway) on both the local users and the traded good traffic. As a result, there is a trade-off between the policy considerations for the local user and traded good markets.

In the absence of congestion, $\tau_{A}^{N W}=\tau_{B}^{N W}=0$ by (21) and (23) and so equation (45) reduces to (for $m=A, B)$ :

$$
\tau_{m}^{T L}=t_{m}^{N W} \frac{\partial X}{\partial \tau_{m}} /\left(\frac{\partial Y_{m}}{\partial \tau_{m}}+\frac{\partial X}{\partial \tau_{m}}\right)
$$

where $t_{m}^{N W}$ are given by (22) and (24) respectively, $\partial X / \partial \tau_{m}>0$ by Lemma 2 and $\partial Y_{m} / \partial \tau_{m}>0$ by Lemma 1 . For country $A$ equation (46) shows, therefore, that, conditional on $X$,

$$
\tau_{A}^{N W}=0<\tau_{A}^{T L}<[(N-1) / N]\left(P_{X} / \varepsilon_{X}\right)=t_{A}^{N W}
$$

As a consequence, the cartel coordination via this domestic transport policy is not as effective as the trade policy (if it were available) in the national welfare-maximizing case. Furthermore, under trade liberalization with uniform tolls, a positive highway toll is imposed on local highway users in country $A$, in contrast to a zero toll under both national and global welfare maximizations. As compared to the national or global welfare maximization, therefore, the full cost incurred by local highway users in country $A$ rises under trade liberalization; consequently, by Lemma 1, the local highway traffic falls and the local highway users are worse off. This is an interesting result, especially given that the impact of trade liberalization on other consumer markets through the corresponding changes in domestic transport policy has not been discussed in the trade literature.

Similarly, the magnitude of country $B$ 's (uniform) highway toll given in (46) is, conditional on $X$, smaller than that under national welfare maximization (i.e., the only charge on the traded good in that case). In particular, for $\left(P_{X} / \varepsilon_{X}\right)-X^{2} P_{X}^{\prime \prime}>0(<0$, respectively), there is also a positive (negative, respectively) toll imposed on the traded good 
in country $B$ under trade liberalization but it is smaller in (absolute) magnitude than that under national welfare maximization. Meanwhile, the same toll is imposed on the local highway users in country $B$, which will increase (decrease, respectively) the full cost incurred by the local highway users and thus decrease (increase, respectively) the local highway traffic (recall that no toll is imposed in both the national and global welfaremaximizing cases if there is no highway congestion). It can thus be concluded that for $\left(P_{X} / \varepsilon_{X}\right)-X^{2} P_{X}^{\prime \prime}>0(<0$, respectively), the local highway users in country $B$ are worse off (better off, respectively) under trade liberalization than under national or global welfare maximization.

It is also noted that in the absence of highway congestion, both countries impose a positive charge on the traded good under trade liberalization if $\left(P_{X} / \varepsilon_{X}\right)-X^{2} P_{X}^{\prime \prime}>0$ (recall a linear demand for the traded good will satisfy this condition), while a subsidy is given to the traded good in the global welfare-maximizing case. This suggests that comparing with the global welfare-maximizing case, the full cost incurred by the traded good will rise under trade liberalization, and thus firms will reduce the traded good output. The result is undetermined, however, if $\left(P_{X} / \varepsilon_{X}\right)-X^{2} P_{X}^{\prime \prime}<0$.

Summarizing the preceding analysis yields the following proposition:

Proposition 5. In the absence of congestion, under trade liberalization with uniform tolls,

(i) a positive highway toll - which is considered as a domestic (internal) transport policy - in the exporting country is used to serve, partially, as a strategic export tax, with its local highway users being worse off; and

(ii) a positive (negative, respectively) highway toll in the importing country is imposed, and its local highway users are worse off (better off, respectively), if $\left(P_{X} / \varepsilon_{X}\right)$ $-X^{2} P_{X}^{\prime \prime}>0(<0$, respectively) than under both the national and global welfare maximizations.

(iii) the traded-good output is less than that under the global welfare maximization if $\left(P_{X} / \varepsilon_{X}\right)-X^{2} P_{X}^{\prime \prime}>0$, which is the case for a linear demand.

An interesting implication of the above analysis is that it may suggest a potential source for the "border effect" noted in the introduction. If discriminatory transport policies are allowed under trade liberalization, trade volume would be limited to the same level as if trade were not free. Even if discriminatory transport policies are not allowed in a free trade agreement, trade may still be limited. Here, the global welfare-maximizing case can be interpreted as the "home-country trade" case whereas our trade liberalization case as the "cross-boundary trade" case in the context of the border. Proposition 5 (iii) then suggests that although trade barriers (export tax, tariff) are removed under trade liberalization, the lack of coordination in pricing congestible domestic transportation facilities (which is regarded as pure domestic/national policies) may induce higher "full" costs which include congestion delay costs - incurred by the traded goods in the cross-boundary trade case (i.e., trade liberalization) than that in the home-country trade case (i.e., global welfare maximization), resulting in less trade volumes in the case with national borders than in the borderless case. The local facilities' congestion and the lack of coordination 
between the countries in their transport policies may suggest a potential explanation for the border effect. ${ }^{17}$

\section{Concluding Remarks}

Strategic trade and transport policies in which transportation of traded goods involves congestible facilities (here, roads or highways) of both the importing and exporting countries have been examined. Meanwhile, there are local users using the highways of their respective countries. It turns out that the local highway user market and the traded good market are related through congestion at the highways. This analysis suggests that the presence of road congestion can have an important effect on strategic trade policies of both countries. In particular, with a perfectly competitive market structure at the exporting industry and hence an absence of the rent-extraction incentive, country $B$ still imposes a positive tariff. Furthermore, after regional free trade blocs remove trade barriers, whether countries can impose discriminatory highway tolls between the local users and the traded-good traffic can have an important implication on the effectiveness of the free trade agreements. With discriminatory tolls, trade liberalization would yield the same equilibrium outcome as that under the national welfare maximization. With uniform tolls, highway tolls, while being regarded as a domestic (internal) policy, may serve partially as strategic trade policies; as a consequence, local highway users tend to be worse off than in the absence of the free trade agreements. Finally, this analysis provides a potential explanation for the well-known "border effect".

This paper has raised some avenues for future research. First, it is important to extend the present analysis to the case of flexible highway capacities, as the capacity investment decisions at transportation facilities are expected to have important implications for both facility congestion and pricings. The infrastructure can also be a public good for trade partners, thus influencing firms' and consumers' behavior as well as interacting with strategic trade policies. Second, this paper focuses on the pricing of a single transportation facility, highway. In practice, highways may be linked to other complementary transportation facilities such as seaports or airports. Thus the pricing at the highways considered in this paper may have external impacts on those other facilities, an issue that deserves further examination. Third, the present framework may be extended so as to allow for potential firm entries in the importing country, or for competition from firms of a third country (as in, e.g., Brander and Spencer, 1985). This raises the possibility that trade and transport policies may be used to strengthen the competitiveness of national firms vis-à-vis the foreign counterparts, as well as to deal with the market power and congestion problems as discussed in the present paper.

${ }^{17}$ Furthermore, since the analysis here highlights the difference in full costs at transportation facilities, including time costs, being a potential source of the border effect, their relationship can be further examined empirically by using transportation time as an additional proxy for transportation costs. Note that only the distance between regions usually serves this purpose in the existing literature (e.g., McCallum, 1995; Anderson and Van Wincoop, 2004). 
Finally, following the early work by Negishi (1972), Falvey (1976) and Cassing (1978), one may want to model transport service as one of the intermediate goods for producing the traded good. In this framework, the transport service considered here i.e., the highways - may be competing with local roads parallel to these highways, or other transportation means (e.g., railway or air transport). As a consequence, exporters may switch among alternative transport modes depending on their costs and congestion levels. More generally, transport services may be competing with other inputs such as capital. One potential advantage of the intermediate goods approach is that it may allow us to explicitly model a monopolistic or oligopolistic transport services sector (recall the analysis is confined to a perfectly competitive transport sector). In such situations, there exists monopsony or oligopsony power in the domestic and foreign transport services sectors, resulting in interesting, yet rather complicated, strategic behaviors at various levels. One way to model such strategic interactions in an intermediate goods framework is to consider a "vertical structure," in which the countries first choose their trade and transport policies, then oligopolistic transport firms first decide, possibly along with other input suppliers, its price and finally exporting firms choose their outputs. It is considered that modeling the transport services sector in such a framework would be an interesting extension of the analysis presented here, although beyond the scope of what the present paper attempts to achieve.

\section{References}

Anderson, J.E. and E. Van Wincoop, 2004, “Trade Costs," Journal of Economic Literature, 42(3), 691-751.

Auquier, A.A. and R.E. Caves, 1978, "Monopolistic Export Industries, Trade Taxes and Optimal Competition Policy,” Economic Journal, 89, 559-581.

Basso, L.J. and A. Zhang, 2007, "Congestible Facility Rivalry in Vertical Structures," Journal of Urban Economics, 61(2), 218-237.

Berechman, J., 2007, "The Social Costs of Global Gateway Cities: The Case of the Port of New York," presentation at the International Conference on Gateways and Corridors, Vancouver, B.C., May 2007.

Brander, J.A., 1995, “Strategic Trade Policy," in Gene Grossman and Kenneth Rogoff(eds.), Handbook of International Economics, Vol. III, Elsevier Science, Amsterdam.

Brander, J.A. and B.J. Spencer, 1981, "Tariffs and the Extraction of Foreign Monopoly Rents under Potential Entry," Canadian Journal of Economics, 14(3), 371-389.

Brander, J.A. and B.J. Spencer, 1984, “Trade Welfare: Tariffs and Cartels," Journal of International Economics, 16, 227-242.

Brander, J.A. and B.J. Spencer, 1985, "Export Subsidies and Market Share Rivalry," Journal of International Economics, 18, 83-100.

Brueckner, J.K., 2002, “Airport Congestion When Carriers have Market Power,” American Economic Review, 92 (5), 1357-1375.

Bulow, J.I., J.D. Geanakoplos, and P.D. Klemperer, 1985, "Multimarket Oligopoly: Strategic Substitutes and Complements," Journal of Political Economy, 93, 488-511. 
Carruthers, R. and J.N. Bajpai, 2002, "Trends in Trade and Logistics: An East Asian Perspective," Working Paper No. 2, Transport Sector Unit, World Bank, Washington, DC.

Cassing, J.H., 1978, “Transport Costs in International Trade Theory: A Comparison with the Analysis of Nontraded Goods," Quarterly Journal of Economics, 92(4), 535-550.

De Borger, B., F. Dunkerley, and S. Proost, 2007, "Strategic Investment and Pricing Decisions in a Congested Transport Corridor," Journal of Urban Economics, 62(2), 294-316.

De Borger, B., S. Proost, and K. Van Dender, 2005, "Congestion and Tax Competition in a Parallel Network," European Economic Review, 49, 2013-2040.

De Jong, G., 2000, "Value of Freight Travel-Time Savings," in: D.A. Hensher and K.J. Button (eds.), Handbook of Transport Modelling, Elsevier Science, Amsterdam.

Dixit, A., 1984, "International Trade Policy for Oligopolistic Industries," Economic Journal, 94 Supplement, 1-15.

Dixit, A., 1986, “Comparative Static for Oligopoly,” International Economic Review, 27, 107-122.

Engel, C. and J. Rogers, 1996, "How Wide is the Border?” American Economic Review, $86,1112-1125$.

Enke, S., 1944, “The Monopsony Case for Tariffs," Quarterly Journal of Economics, 58, 229-245.

Evans, C., 2003, “The Economic Significance of National Border Effects," American Economic Review, 93(4), 1291-1312.

Everett, S., 2006, “A National Regulator Smoothing Supply Chain Bottlenecks? The Case of Dalrymple Bay Coal Terminal," presented at the International Association of Maritime Economists Conference, Melbourne, July 2006.

Falvey, R., 1976, "Transport Costs in the Pure Theory of International Trade," Economic Journal, 86, 536-550.

Gausch, J.L. and J. Kogan, 2001, "Inventories in Developing Countries: Levels and Determinants, a Red Flag on Competitiveness and Growth," World Bank Working Paper, No. 2552.

Hummels, D., 2001, “Time as a Trade Barrier,” GTAP Working Paper, No. 18.

Kose, M.A. and K. Yi, 2001, "International Trade and Business Cycles: Is Vertical Specialization the Missing Link?" American Economic Review, 91(2), 371-375.

Krugman, P., 1991a, "Increasing Returns and Economic Geography," Journal of Political Economy, 99, 483-499.

Krugman, P., 1991b, Geography and Trade, MIT Press, Cambridge MA.

Krugman, P. and A.J. Venables, 1995, "Globalization and the Inequality of Nations," Quarterly Journal of Economics, 110(4), 857-880.

Laussel, D. and R. Riezman, 2006, "Transport Costs and North-South Trade," AsiaPacific Journal of Accounting \& Economics, 13(2), 111-122.

Levinson, D. and B. Smalkoski, 2003, "Value of Time for Commercial Vehicle Operators in Minnesota," Transportation Research Board (TRB) International Symposium on Road Pricing, University of Minnesota.

Limao, N. and A.J. Venables, 2001, “Infrastructure, Geographical Disadvantage, Transport Costs and Trade," World Bank Economic Review, 15(3), 451-479. 
McCallum, J., 1995, "National Borders Matter: Canada-US Regional Trade Patterns," American Economic Review, 85(3), 615-623.

McCann, P., 2005, “Transport Costs and New Economic Geography,” Journal of Economic Geography, 5, 305-318.

Negishi, T., 1972, "Equilibrium and Efficiency of Free Trade," in Henri Theil (ed.), General Equilibrium Theory and International Trade, Chapter 2, 28-38, NorthHolland, Amsterdam and London.

Parsley, D.C. and S. Wei, 2001, "Explaining the Border Effect: The Role of Exchange Variability, Shipping Costs, and Geography," Journal of International Economics, 55, 87-105.

Samuelson, P.A., 1954, "The Transfer Problem and Transport Costs, II: Analysis of Effects of Trade Impediments," Economic Journal, 64 (254), 264-289.

Small, K.A., 1992, Urban Transportation Economics, Harwood Academic Publishers, Chur, Switzerland.

Small, K.A. and E.T. Verhoef, 2007, The Economics of Urban Transportation, Routledge, London.

US DOT, 2003, "Revised Departmental Guidance: Valuation of Travel Time in Economic Analysis," U.S. Department of Transportation, Washington, DC.

Wei, S., 1996, "Intra-National versus International Trade: How Stubborn Are Nations in Global Integration?” NBER Working Papers, No. 5531.

Yuen, A., L.J. Basso and A. Zhang, 2007, "Effects of Gateway Congestion Pricing on Optimal Road Pricing and Hinterland," Journal of Transport Economics and Policy, forthcoming.

Zhang, A. and Y. Zhang, 2006, "Airport Capacity and Congestion When Carriers have Market Power," Journal of Urban Economics, 60, 229-247. 